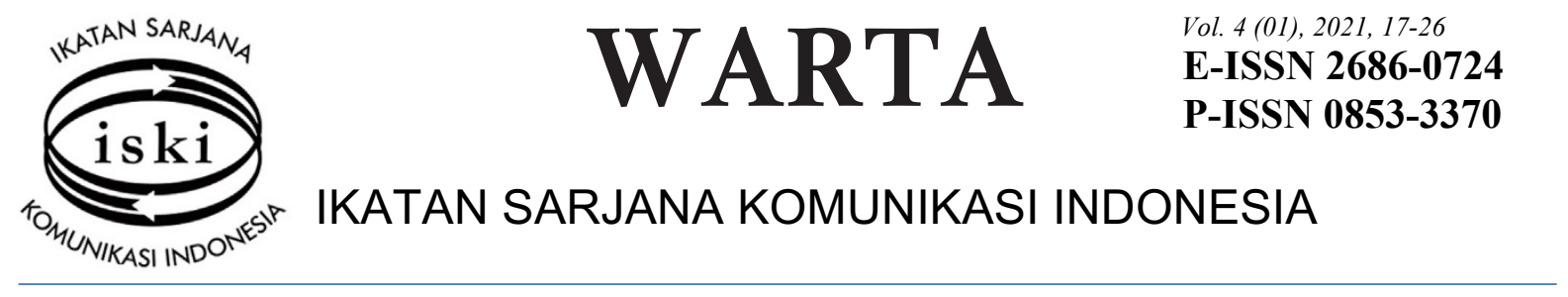

\title{
Konstruksi Pemberitaan Kepala Daerah di Kota Makassar Terkait COVID-19
}

\author{
http://dx.doi.org/10.25008/wartaiski.v4i1.100
}

\author{
Nurjannah $^{1 *}$, Alem Febri Sonni ${ }^{2}$ \\ ${ }^{1,2}$ Departemen Ilmu Komunikasi, Universitas Hasanuddin \\ Jl. Perintis Kemerdekaan Km 10, Tamalanrea Indah, Makassar 90245 - Indonesia \\ *Email Korespondensi: usmanurjannah@gmail.com
}

Submitted: 25/02/2021, Revised: 28/05/2021, Accepted: 15/06/2021

Accredited by Kemristekdikti No. 30/E/KPT/2019

\begin{abstract}
This study aims to see the construction of the media and the media's tendency towards Acting Mayor of Makassar, Prof. Yusran Jusuf and Governor of South Sulawesi Prof. Nurdin Abdullah in issuing a policy for handling the COVID-19 pandemic case, in the online media Makassar Terkini. id edition 16 to 27 May 2020. This research uses the Robert N. Entman framing analysis method, using a qualitative approach. The results showed that the overall problem definition of the coverage of the COVID-19 pandemic handling policy Yusran Jusuf contradicts the policy of Nurdin Abdullah. Diagnose cause Yusran Jusuf wanted to relax Large-Scale Social Restrictions amid the increasing cases of the COVID-19 pandemic in South Sulawesi, especially in Makassar City, so the Governor gave a warning to Yusran Jusuf, make moral judgment Yusran Jusuf must make rules according to geographical conditions, Treatment recommendation offered is a policy for handling the COVID-19 pandemic according to the direction of the central government, while at the same time creating good coordination.
\end{abstract}

Keywords: Framing analysis; mayor of Makassar; online media; Makassar terkini.id

\begin{abstract}
Abstrak
Penelitian ini bertujuan melihat kontruksi media online Makassar Terkini.id, edisi 16 hingga 27 Mei 2020 terkait pemberitaan kebijakan penanganan kasus pandemi COVID-19 dari Pejabat Wali Kota Makassar, Prof. Yusran Jusuf dan Gubernur Sulawesi Selatan, Prof. Nurdin Abdullah. Penelitian menggunakan pendekatan kualitatif dengan analisis framing Robert N. Entman. Define problem pemberitaan menunjukkan kebijakan penanganan pandemi COVID-19 dari Pejabat Wali Kota Makassar, Prof. Yusran Jusuf bertentangan dengan kebijakan Gubernur Sulawesi Selatan, Prof. Nurdin Abdullah. Diagnose cause Prof. Yusran Jusuf ingin melakukan pelonggaran Pembatasan Sosial Berskala Besar di tengah meningkatnya kasus pandemi COVID-19 di Kota Makassar, sehingga Gubernur memberikan teguran kepada Prof. Yusran Jusuf. Make moral judgment, Prof. Yusran Jusuf harus membuat aturan sesuai kondisi geografis, dan Treatment recommendation menyarankan agar kebijakan yang diambil sesuai arahan pemerintah pusat sekaligus menciptakan koordinasi yang baik.

Kata Kunci: Analisis framing; wali kota makassar; media online; Makasssar terkini.id.
\end{abstract}

\section{PENDAHULUAN}

Media massa memberitakan sebuah informasi atau peristiwa karena mengandung prominence, human intrenst, proximity, timeliness, magnitude (Siregar, 2007) seperti, kebijakan penanganan COVID-19 antara Pejabat Wali Kota Makassar, Prof. Yusran Jusuf dan Gubernur Sulawesi Selatan, Prof. Nurdin Abdullah. Berita tentang kedua kepala daerah itu menarik diberitakan karena kebijakan antara Prof. Yusran Jusuf dan Prof. Nurdin Abdullah dalam menangani COVID-19 saling bertentangan.

Media turut meramaikan pemberitaan COVID-19 termasuk bagaimana kinerja pemerintah dalam menangani pandemi COVID-19 dan dampaknya bagi masyarakat. Media online memiliki keunggulan 
berupa kecepatan dan kemudahan meng-update situasi pandemi COVID-19 (Kheyene, Mutia, \& Nalal, 2020). Kebijakan pemerintah tidak terlepas dari sorotan media baik media cetak, elektronik dan media online (Riky, 2020).

Berita merupakan realitas yang telah mengalami proses kontruksi. Teks pemberitaan sudah dikontruksi oleh media (Eriyanto, 2002). Salah satu media online di Sulawesi Selatan adalah Makassar Terkini.id yang gencar memberitakan penanganan COVID-19 di Kota Makassar. Media itu memberi porsi besar bagi pemberitaan Pejabat Wali Kota Makassar, Prof. Yusran Jusuf dalam menangani kasus pandemi COVID-19. Fenomena tersebut, kemudian dikontruksi oleh media menjadi realitas baru berupa berita pelemahan kebijakan Prof. Yusran yang tidak sejalan dengan instruksi Gubernur Sulawesi Selatan, Prof. Nurdin Abdullah.

Media dalam mengangkat isu atau topik tidak selalu sama dengan kenyataan atau realitas yang sesungguhnya (Eriyanto, 2019). Selanjutnya, Charles (1985) menambahkan, media massa melakukan seleksi terhadap isu yang disajikan kepada khalayak. Itu sebabnya media massa memiliki kemampuan mengarahkan isu tertentu untuk diterima khalayak dan menjadikannya sebagai suatu isu penting.

Makassar Terkini.id menampilkan kontradiksi antara Wali Kota Makassar dan Gubernur Sulsel. Media online itu cenderung sering mengangkat citra Prof. Yusran yang dapat dilihat sebagai kontruksi realitas, mulai dari penempatan tema berita sekaligus pemilihan narasumber. Berita edisi 26 Mei 2020 menjadi contohnya. Berita itu berjudul "Anggota DPRD Makassar Minta Yusran Jusuf Terbiasa dengan Kritik. Isinya: "Pak Wali tidak melakukan pelonggaran. Hanya memang ada prioritas. Pikiran Pak Wali 11-12 dengan Pak Jokowi".

Pada dasarnya, isi media dikontruksi oleh jurnalis dari berbagai realitas yang dipilihnya. Sobur dalam (Riris, Genep, Roswita, \& Lusia, 2020, Hamad, 2004) menambahkan berita yang dihasilkan jurnalis, merupakan kumpulan realitas yang disusun sehingga membentuk sebuah cerita bermakna. Senada dengan Stuart Hall, Eriyanto (2011) menyatakan, setelah media membentuk realitasnya sendiri, media kemudian menjabarkan realitas tersebut dengan cara tertentu yang disebut kontruksi berita. Dalam proses kontruksi berita, unsur seperti teks berita tidak serta merta ditempatkan begitu saja.

Menurut Aart van Zoest dalam (Alex, 2009), sebuah teks dalam berita merupakan suatu bentuk manipulasi pembaca ke ideologi tertentu. Raymond Williams dalam (Alex, 2009) menjabarkan ideologi adalah himpunan ide-ide berisi seperangkat kepentingan dari kelompok tertentu. Mettew Kieran dalam (Eriyanto, 2011) menambahkan, terbentuknya sebuah berita diproduksi oleh ideologi yang dominan dalam suatu wilayah.

Setiap media memiliki cara tersendiri dalam memberitakan pemberitaan Prof. Yusran Jusuf dan Prof. Nurdin Abdullah. Perbedaan sudut pemberitaan berangkat dari pembingkaian (framing) antara media yang satu dengan media lainnya. Selain itu, setiap media memiliki ciri tersendiri dalam menyajikan berita (Ruri, Zainal, \& Airlangga, 2020). Biasanya media online menampilkan isi yang sama dengan judul yang berbeda, namun tidak menutup kemungkinan isi yang berbeda, sekaligus gaya yang berbeda-beda (Zainal, 2019). Riky Rakhmadani (2020) menambahkan secara umum media massa memiliki kecenderungan melakukan peliputan dengan mempertimbangkan nilai berita yang dipilih berdasarkan proximity, magnitude, faktualitas, aktualitas, dan kemanfaatan tema.

Produksi berita di ruang redaksi dikontrol penuh sebelum diterbitkan. Kontrol merupakan bagian framing dari media yang bersangkutan. Menurut Eriyanto (2009), framing adalah kontruksi realitas yang berpusat pada penyaluran ide atau pokok pikiran wartawan dalam bentuk berita yang dipublikasikan ke khalayak. Robert N. Entman menambahkan, terdapat dua dimensi besar dalam framing yakni, seleksi dan kecenderungan.

Setiap kasus atau peristiwa yang diberitakan, pekerja media memilah aspek yang ingin ditonjolkan atau dihilangkan, semua itu mengarah ke konsep framing. Framing dalam perspektif komunikasi, dipakai untuk membedah cara-cara ideologi media saat mengkontruksikan berita (Alex, 2009). Pemilihan tersebut, tidak terlepas dari kepentingan masing-masing media baik politik, ekonomi, dan ideologi. Media dalam mengkontruksikan realitas, juga tidak terlepas dari pandangan, bias, sekaligus pemihak yang ada di belakangnya (Eriyanto, 2009).

Dengan demikian, dapat disimpulkan berita adalah hasil pemikiran atau sudut pandang individu atau sekolompok orang yang berada dalam kelompok redaksional, yang mengacu pada kebijakan dan ideologi yang disepakati. Ideologi dan framing, merupakan satu kesatuan yang saling 
berkesinambungan. Wartawan dalam menkontruksi sebuah realitas melakukan pilihan atas peristiwa yang akan dijadikan sebagai realitas.

Dari 20 media online di Sulawesi Selatan, Makassar Terkini menduduki posisi kedua berdasarkan hasil akses tertinggi (Rank, 2020). Makassar Terkini menempati rangking ke-189 untuk jenis media lokal secara nasional, sedangkan untuk katagori global berada di peringkat 9.315. Data tersebut, membuktikan Makassar Terkini menjadi salah satu media yang paling sering diakes oleh pembaca.

Penelitian framing pada media online biasa digunakan dengan tema yang berbeda-beda seperti dilakukan Ardhina (2018), Xena (2014), Achmad, Mayasari, \& Siti (2020) serta berbagai penelitian lainnya. Berbeda dengan mereka, penelitian ini berfokus pada upaya memahami kontruksi yang dilakukan Makassar Terkini.id terhadap sosok Prof. Yusran sebagai Pejabat Wali Kota Makassar dan kecenderungan yang ditonjolkan media itu dalam memberitakan Prof. Yusran Jusuf versus Gubernur Sulawesi Selatan Prof. Nurdin Abdullah.

\section{KERANGKA TEORI}

Media online dikenal juga sebagai media digital dan disajikan secara online di internet. Media online terbagi atas dua pengertian yakni, umum dan khusus. Secara umum media online adalah segala jenis media yang dapat diakses melalui internet, berbasis telekomunikasi dan multimedia. Secara khusus, media online merupakan sarana komunikasi online dalam konteks komunikasi massa (Ammar $\&$ Dewi, 2020). Kehadiran media online menyebabkan penyebaran peristiwa di seluruh dunia menjadi sangat cepat. Informasi yang disajikan media online sama dengan media berita konvensional, berupa teks berita yang dapat menarik minat pembaca (Margianto \& Syaefullah, 2012).

Intensitas pemberitaan setiap media cukup beragam, rata-rata menampilkan berita straight news. Berita yang terlalu panjang dibagi dalam beberapa halaman web page. Untuk meningkatkan jumlah berita, sekaligus durasi pemberitaan, angle berita dibuat dalam beberapa bagian. Hal tersebut dilakukan untuk menghindari rasa bosan pembaca yang rata-rata mengunjungi halaman web selama 10 menit (Romli, 2012).

\section{Analisis Framing}

Secara sederhana framing adalah membingkai suatu peristiwa (Bungin, 2006). Sobur sebagaimana dikutip Henny, Nuryani, \& Retno (2019) mengatakan, analisis framing bertujuan untuk mengetahui perspektif atau sudut pandang wartawan dalam menyeleksi suatu isu dan memberikan penonjolan pada teks yang disajikan. Senada dengan itu, Muhaemin \& Sanusi (2019) mengatakan, framing dimaknai sebagai cara media menyajikan peristiwa dengan memberikan penekanan pada aspek-aspek suatu peristiwa, sekaligus bagaimana media bercerita atas realitas yang telah dikontruksi.

Framing memperlihatkan cara pandang wartawan atau media dalam menyeleksi, mengorganisir, menulis dan menempatkan suatu isu. Framing juga merupakan cara setiap media untuk membedah, mengkontruksikan fakta, sekaligus sebagai ciri ideologi antara media yang satu dengan media yang lainnya (Ronda, 2018). Eriyanto (2019) menambahkan inti dari framing adalah dilihat dari pembentukan pesan dari teks berita oleh media, dan bagaimana peristiwa dikontruksikan oleh media.

Senada dengan itu, Ronda (2018) menyebutkan analisis framing adalah bagaimana pesan diartikan sehingga dapat diinterpretasikan secara efisien. Agar kontruksi realitas yang dibentuk oleh media dapat dimengerti khalayak, media menggunakan teks berita berupa bahasa agar dapat dipahami dan dimaknai oleh pembaca (Sophia, Ira, \& Dedi, 2016).

Realitas tidak muncul begitu saja namun disaring sesuai dengan cara pandang setiap manusia. Littlejohn, dan Peter L. Berger dalam Karman (2013) menjelaskan media bukanlah cerminan realitas dari agen kontruksi. Wiliam A. Gamson, dikutip Karman (2013) menjelaskan kontruksi sosial terjadi pada dua level yakni level individual dan level wacana.

\section{METODE PENELITIAN}

Penelitian ini adalah interpretatif dengan pendekatan kualitatif untuk menggambarkan aspek tertentu dari sebuah realitas yang dibingkai oleh Makassar.Terkini.id menjadi sebuah berita yang kemudian menjadi realitas bagi masyarakat, terkait polemik pemberitaan Wali Kota Makassar Prof. Yusran Jusuf versus Gubernur Sulsel, Prof. Nurdin Abdullah. Penelitian ini menggunakan analisis 
framing model Robert N. Entman yang menekankan dua dimensi: seleksi isu dan penonjolan (salience) isi teks berita (Eriyanto, 2011).

Peneliti mengumpulkan data yang relevan dengan objek penelitian, berupa data primer yakni kumpulan berita Prof. Yusran Jusuf dan Prof. Nurdin Abdullah di media online Makassar.Terkini.id periode 13 Mei 2020 sampai 25 Juni 2020. Data sekunder berupa website media online, jurnal online, serta buku-buku yang berkaitan dengan topik penelitian. Setelah itu, peneliti melakukan analisis data mengunakan empat elemen framing Entman: Define Problems (pendefinisian masalah), Diagnose Causes (memperkirakan penyebab masalah), Make Moral Judgement (membuat keputusan moral) dan Treatment Recommendation (menekankan penyelesaian)

\section{HASIL PENELITIAN}

Proses analisis framing model Robert N. Entman terdiri atas komponen pendefenisian masalah, memperkirakan sumber atau penyebab masalah, membuat keputusan moral dan menekankan penyelesaian. Dari enam judul berita online yang dikumpulkan mulai 13 Mei 2020 sampai 25 Juni 2020, masing-masing berita dianalisis sesuai dengan model analisis framing Robert N. Entman, mulai dari pendefenisian masalah, menentukan sumber penyebab masalah, menentukan keputusan moral, dan menekankan penyelesaian.

Dalam proses analisis framing model Robert N. Entman, setiap melakukan analisis pemberitaan, terlebih dahulu diurutkan komponen-komponen model analisis framing-nya. Selanjutnya, setiap komponen dilengkapi dengan bukti teks berita.

Berikut ini adalah analisisnya. Berita pertama berjudul: "Nurdin Abdullah: Usulan Pembukaan Mal Masih Dikaji" edisi 16 Mei 2020, pukul 11:33 WITA. Pada berita tersebut, framing yang ingin diperlihatkan Makassar Terkini.id dalam teks berita adalah Gubernur Sulsel, Prof. Nurdin Abdullah mengklarifikasi isu yang beredar terkait akan dibuka mall di Makassar. Gubernur Sulsel menyampaikan pembukaan mal masih dalam kajian.

Selanjutnya, Gubernur mengungkapkan meskipun banyak pihak meminta untuk melakukan pelonggaran lock-down, namun Gubernur pada kutipan langsung mengatakan tidak akan melakukan pelonggaran Pembatasan Sosial Berskala Besar (PSBB) jika kasus COVID-19 masih meningkat. Teks berita kemudian ditutup dengan imbauan Gubernur Sulsel melalui Tim Gugus Tugas mengimbau kepada masyarakat agar tetap mematuhi aturan pemerintah.

Berdasarkan model analisis framing Robert N. Entman, dari segi komponen pendefenisian masalah adalah informasi mal di Makassar akan dibuka dan Gubernur menyampaikan hal itu masih dalam kajian dan belum ada keputusan. Bukti teks pendefenisian masalah berita pertama adalah:

Gubernur Sulawesi-Selatan Nurdin Abdullah menyampaikan klarifikasi terkait informasi yang beredar bahwa mal di Makassar akan dibuka.

Nurdin menjelaskan, hal tersebut masih dalam kajian dan belum ada keputusan.

Saya juga ingin meluruskan pemberitaan mengenai mal di Makassar yang akan dibuka. Hal ini masih dalam kajian dan belum ada keputusan konkrit, apalagi Makassar sementara PSBB, kata Nurdin Abdullah, Sabtu 16 Mei 2020.

Selanjutnya yang menjadi sumber atau penyebab masalah pada berita pertama adalah banyaknya masukan dari pihak mal untuk melakukan pelonggaran. Bukti teks dalam berita pertama antara lain: walaupun banyak masukan dari pemilik mal yang meminta pelonggaran. Hal ini mengingat usaha mereka sudah tutup hampir dua bulan.

Komponen selanjutnya adalah membuat keputusan moral. Pada berita pertama, keputusan moral yang diambil terkait isu pembukaan mal adalah gubernur mengatakan tidak ada pelonggaran PSBB, jika jumlah COVID-19 masih meningkat. Bukti teks berita antara lain: "Jadi saya tegaskan sekali lagi, pelonggaran PSBB tidak akan kita lalukan jika tren peningkatan pasien COVID-19 masih sangat terjadi”. Upaya ini mendukung kebijakan Makassar yang sudah memperpanjang PSBB.

Komponen penekanan penyelesaian masalah pada berita pertama adalah Gubernur Sulsel melalui Gugus Tugas mengimbau masyarakat untuk terus patuh terhadap anjuran pemerintah, agar ekonomi tidak ikut terpapar. Bukti teks dalam berita antara lain: 
Tim Gugus Tugas terus bekerja keras dan terus mengimbau kepada masyarakat agar mengikuti anjuran pemerintah untuk menerapkan physical distancing (pembatasan fisik), pakai masker, rajin cuci tangan dalam beraktivitas. "Sampai saat ini telah banyak saudara-saudara kita terpapar COVID-19, namun kita berusaha sekuat tenaga agar ekonomi kita tidak ikut terpapar," sebut Nurdin.

Berita kedua dengan judul "Kasus COVID-19 Tembus 606 dan Terus Naik, Makassar Stop PSBB dan Bolehkan Toko Buka", edisi 21 Mei 2020, pukul 12:33 Wita. Analisis framing yang ditunjukkan Makassar Terkini.id adalah meskipun kasus COVID-19 di Makassar mencapai 606 orang, namun Pemerintah Kota Makassar tidak menghiraukan angka tersebut. Hal itu terlihat pada ketegasan Walikota Makassar Prof. Yusran Jusuf untuk tidak memperpanjang PSBB, mengikuti peraturan yang telah dibuat oleh Badan Penanggulangan Bencana Nasional (BNPB). Prof. Yusran mengatakan setelah PSBB selesai, maka toko boleh buka dengan tetap mematuhi protokol kesehatan.

Segi pendefenisian masalah pada berita kedua menunjukkan, angka kasus COVID-19 di Kota Makassar:

Makassar - Kasus COVID-19 khusus di Kota Makassar mencapai angka 606 pasien per Kamis 21 Mei 2020 kemarin dengan penambahan 18 pasien sepanjang hari kemarin. Angka itu berkontribusi terhadap peningkatan kasus covid Sulsel yang mencapai angka 1.135 per Kamis kemarin dengan penambahan kasus baru sebanyak 34 pasien.

Perkiraan sumber atau penyebab masalah pada berita kedua adalah, di tengah meningkatnya kasus COVID-19, Pemerintah Kota Makassar tidak melanjutkan Pembatasan Sosial Berskala Besar yang dinyatakan dalam teks berita:

Namun di tengah peningkatan angka kasus tersebut, Pemerintah Kota Makassar memilih untuk tidak melanjutkan Pembatasan Sosial Berskala Besar atau PSBB. Pemkot Makassat bahkan membolehkan toko toko untuk beroperasi kembali. Penjabat Wali Kota Makassar, Yusran Jusuf telah menegaskan tak akan memperpanjang pembatasan sosial berskala besar (PSBB) untuk tahap ketiga. Yusran mengungkapkan akan mengganti Peraturan Wali Kota (Perwali) yang selama ini menjadi payung hukum selama penerapan PSBB dengan Perwali baru. PSBB jelas tidak dilanjutkan, tetapi kita sudah membuat Perwali baru tentang penerapan protokol kesehatan, terang Yusran, Kamis, 21 Mei 2020.

Melangkah ke keputusan moral pada berita kedua yakni, terdapat Peraturan Walikota yang baru, mengikuti peraturan Badan Penanggulangan Bencana Nasional. Hal itu termuat dalam teks berita:

Menurut Yusran, Perwali yang baru nantinya akan mengikuti peraturan yang telah dibuat oleh Badan Penanggulangan Bencana Nasional (BNPB). Kurang lebih hampir sama. Kita mengadopsi protokol kesehatan yang dibuat oleh BNPB Pusat," ucapnya.

Penekanan penyelesaian pada berita kedua adalah, setelah PSBB berakhir, toko boleh buka sepanjang menerapkan prosedur Kesehatan. Hal terlihat pada teks berita:

Yusran mengatakan semua toko setelah PSBB berakhir akan diperbolehkan untuk beroperasi selama menerapkan protokol kesehatan. Kalau kemarin kan ada beberapa Toko ditutup, kalau sekarang semua boleh membuka, sepanjang dia menerapkan prosedur Kesehatan. Aturannya sama, antara lain social distancing, jaga jarak, pake masker. Hanya memang lebih dibuka ruang," terang mantan Dekan Fakultas Kehutanan Unhas tersebut.

Berita ketiga dengan judul: "PSBB Makassar Tahap 2 Berakhir Besok, Begini Tanggapan Anggota Komisi A DPRD” terbit pada 21 Mei 2020 pukul 17:34 WITA. Framing Makassar Terkini.id adalah tanggapan Anggota Komisi A DPRD, Kasrudi, terkait PSBB yang akan berakhir. Menurut Kasrudi, jika PSBB berakhir, dia ikut dengan keputusan Pemerintah Kota Makassar. Makassar Terkini.id juga memperlihatkan, Kasrudi menganggap wajar jika toko mulai dibuka, karena perekonomian perlu diperhatikan asalkan dengan protokol kesehatan tetap diperketat.

Dari komponen analisis pendefenisian masalah pada berita ketiga, termuat dalam teks berita Makassar Terkini.id: Masa pembatasan sosial berskala besar (PSBB) tahap kedua di Kota Makassar 
akan berakhir besok, Jumat 22 Mei 2020. Sumber atau penyebab masalah pada berita ketiga adalah tanggapan Anggota Komisi A DPRD Kota Makassar, Kasrudi yakni: Menanggapi itu, Anggota Anggota Komisi A DPRD Kota Makassar Kasrudi mengaku sepakat bila PSBB berlanjut ke tahap ketiga.

Ia mengatakan bila mengacu pada tren angka kasus positif COVID-19, jumlahnya semakin meningkat seiring dengan gencarnya pemerintah kota melakukan tes massal. "Tak apa dilanjutkan, saya berharap PSBB kali ini memiliki sanksi yang membuat orang jerah," kata dia kepada terkini.id, Kamis, 21 Mei 2020. Namun bila PSBB hanya sampai tahap kedua, ia mengatakan tetap mengikuti keputusan pemerintah kota. "Yang perlu digaris bawahi adalah perlu Perwali lagi yang mengatur soal COVID19 dan protokol kesehatan," kata dia.

Terkait keputusan moral pada berita ketiga yakni, "ekonomi di tengah pandemi COVID-19 perlu diperhatikan" terlihat pada teks berita antara lain: "Di lain sisi, Ia menyebut sisi ekonomi di tengah pandemi memang perlu perhatian". Pasalnya, jumlah pemutusan hubungan kerja di Kota Makassar semakin meningkat. "Wajarlah memang membuka pertokoan atau pabrik-pabrik sehingga tidak banyak yang di PHK," kata dia.

Terakhir, penekanan penyelesaian pada berita ketiga adalah perketat protokol kesehatan, sesuai dengan teks berita: "Tapi harus ada protokol kesehatan yang mumpuni. Karena kalau tidak maka membludak kasus COVID-19," cetusnya. "Agar protokol kesehatan tetap dijalankan dan diperketat, seperti Pasar Butung dan tempat keramaian lain," terangnya. Penjabat Wali Kota Makassar Yusran Jusuf menekankan, dalam menangani pandemi COVID-19 yang harus diperhatikan adalah protokol kesehatan. "Tidak apa-apa keluar yang penting protokol kesehatan (diterapkan)," kata dia.

Berita keempat dengan judul: "Nurdin Abdullah Minta Pj. Wali Kota Makassar Hati-hati Keluarkan Kebijakan”, terbit 26 Mei 2020, pukul 9:14 WITA. Makassar Terkini.id membingkai berita tersebut dengan menonjolkan ketegasan Prof. Nurdin Abdullah sebagai Gubernur Sulsel. Dia menegur $\mathrm{Pj}$. Wali Kota Makassar karena menganggap kebijakan yang dikeluarkan walikota di tengah pandemi COVID-19 dapat merugikan masyarakat, sekaligus menambah penyebaran COVID-19. Prof. Nurdin Abdullah menuturkan, setiap kebijakan yang dikeluarkan Pj. Wali Kota Makassar, harus berkoordinasi dengan Pemprov Sulsel dalam menangani pengurangan angka kasus COVID-19.

Framing berita keempat terlihat jelas pada komponen pendefinisian masalah yaitu menunjukkan Gubernur menegur Pejabat Wali Kota Makassar Prof. Yusran Jusuf. Hal itu terlihat pada teks berita: Gubernur Sulsel Nurdin Abdullah memberikan teguran ke Penjabat Wali Kota Makassar Yusran Jusuf, agar tidak serampangan dalam mengeluarkan kebijakan di tengah pandemi COVID-19.

Sumber atau penyebab masalah pada berita keempat adalah Prof. Yusran memperbolehkan diadakannya resepsi pernikahan, padahal Pemprov Sulsel meminta masyarakat untuk tetap di rumah, sebagaimana terlihat pada teks berita:

Kebijakan Yusran yang membolehkan digelarnya resepsi pernikahan, di tengah kampanye Pempov Sulsel meminta warga beraktifitas di rumah saja sangat beresiko. Kita sedang gencarnya meminta masyarakat untuk tetap di rumah saja, justru Pj Wali Kota membolehkan masyarakat berkumpul di luar dengan membolehkan pelaksanaan resepsi pernikahan. Keputusan ini terlalu dini, dan tidak mempertimbangkan dampaknya," ujar Nurdin, Selasa 26 Mei 2020.

Keputusan moral pada berita keempat yakni, Gubernur menyarankan untuk menjalin koordinasi Pemkot Makassar dengan Pemprov Sulsel, termuat dalam teks berita: Nurdin menuturkan, seharusnya Pj. Wali Kota berkoordinasi dengan Pemprov Sulsel dalam setiap keputusannya. Apalagi ini menyangkut keselamatan banyak orang. Membuka ruang resepsi pernikahan dibolehkan, sama saja memberi ruang penyebaran COVID-19.

Setelah itu, terdapat penekanan penyelesaian pada berita keempat, yakni fokus menekan penyebaran COVID-19, sebagaimana terlihat pada teks dalam berita:

Fokus kita saat ini bagaimana terus menekan penyebaran COVID-19 tidak semakin banyak. Harusnya kita menghargai apa yang sudah jalan sebelumnya, bagaimana pejabat sebelumnya getol melakukan itu. Harusnya juga kita menghargai pengorbanan para tim medis yang sudah bekerja keras, mereka rela meninggalkan keluarga demi mencegah dan menyelamatkan pasien COVID-19.

Berita kelima dengan judul "Anggota DPRD Makassar Minta Yusran Jusuf Terbiasa dengan Kritik", terbit pada 26 Mei 2020 pukul 14:40 WITA. Makassar Terkini.id membingkai Wakil Ketua 
DPRD Kota Makassar, Adi Rasyid Ali, dengan mengatakan Pejabat Wali Kota Makassar Yusran Jusuf siap menerima kritikan karena persoalan di Makassar cukup dinamis dan sangat peka terhadap kebijakan pemerintah.

Selanjutnya Makassar Terkini.id memperlihatkan Wakil Ketua DPRD Kota Makassar Adi Rasyid Ali menyebut upaya Prof. Yusran Jusuf menangani COVID-19 menyerupai langkah yang ditempuh Presiden Joko Widodo. Wakil Ketua DPRD Kota Makassar, Adi Rasyid Ali menyebut konsep new normal Prof. Yusran Jusuf juga dapat meningkatkan imunitas tubuh.

Dari segi pendefinisian masalah di berita kelima adalah penjabat Wali Kota Makassar Yusran Jusuf harus siap menghadapi kritikan, terlihat pada berita:

Wakil Ketua DPRD Kota Makassar Adi Rasyid Ali mengatakan, Penjabat Wali Kota Makassar Yusran Jusuf harus siap menghadapi setiap kritikan. Karena warga Kota Makassar sangat dinamis. Sangat peka terhadap kebijakan pemerintah.

Sumber atau penyebab masalah berita kelima disebabkan persoalan di Kota Makassar terlihat dalam teks berita:

"Program jangka pendek pasti ada kritik sana-sini, itu biasa. Saya yakin pak wali punya kemampuan manajerial yang tinggi untuk menjawab berbagai persoalan di Makassar," kata Adi saat silaturahmi di Gedung DPRD Kota Makassar, Selasa 26 Mei 2020.

Berikutnya keputusan moral pada berita keloma adalah upaya Prof. Yusran itu sama dengan langkah Presiden Joko Widodo, sebagaimana ditulis pada teks berita:

Legislator PDI Perjuangan Mesakh Rantepadang menyebut upaya Pj Wali Kota Yusran dalam menangani pandemi COVID-19 menyerupai langkah yang ditempuh Presiden Joko Widodo. Ia juga mendukung konsep new normal berbasis kearifan lokal yang digulirkan Yusran. "Pak Wali tidak melakukan pelonggaran. Hanya memang ada prioritas. Pikiran Pak Wali 11-12 dengan Pak Jokowi," sebut Mesakh.

Penekanan Penyelesaian pada berita kelima adalah adanya konsep new normal untuk meningkatkan daya tahan tubuh seperti ditulis pada teks dalam berita:

Konsep new normal yang digagas oleh Yusran Jusuf berisi lima protokol kesehatan yakni penggunaan masker, jaga jarak, rutin cuci tangan, olah raga, dan pemenuhan nutrisi lokal untuk meningkatkan daya tahan tubuh masyarakat dengan mengonsumsi tanaman lokal seperti Jahe, Kunyit, Mengkudu dan sejenisnya. Konsep new normal yang disampaikan Pak Wali dapat diterapkan di lorong-lorong. Petani lorong dapat menanam tanaman herbal yang dapat dikonsumsi warga untuk meningkatkan imunitas tubuh, " ujar legislator Partai Nasdem Mario David.

Berita keenam dengan judul "Ketua Komisi A DPRD Tanggapi Penerapan New Normal di Makassar" terbit pada 27 Mei 2020 pukul 21:17 WITA. Makassar Terkini.id membingkai berita dengan memperlihatkan tanggapan Ketua Komisi A DPRD Kota Makassar, Supratman, terkait new normal. Supratman mengatakan new normal merupakan kebijakan pemerintah pusat. Supratman menilai Pejabat Wali Kota Makassar Prof. Yusran Jusuf paham akan kondisi Kota Makassar sehingga mampu membuat aturan yang tetap sesuai dengan aturan pusat. Sebelumnya, Prof. Yusran Jusuf mengaku akan merapkan konsep new normal berbasis kearifan lokal untuk memperkuat herd imunity.

Analisis framing berita keenam dapat dilihat dari pendefinisian masalah, menunjukkan membahas new normal, termuat pada teks berita: "Ketua Komisi A DPRD Kota Makassar, Supratman angkat bicara perihal new normal atau kenormalan baru dalam menghadapi pandemi COVID-19".

Penyebab masalah atau sumber masalah pada berita keenam karena adanya kebijakan pemerintah pusat, seperti terlihat dalam teks berita: "Kita lihat dulu perkembangan new normal karena ini kebijakan pemerintah pusat, sehingga apapun kondisinya pasti kita ikut dengan pusat," kata dia, Rabu, $27 \mathrm{Mei} 2020$.

Keputusan moral yang diambil pada berita keenam, menilai Pejabat Wali Kota Makassar Yusran Jusuf paham kondisi Makassar yang dapat dilihat dalam teks berita: 
Di sisi lain, ia menilai Penjabat Wali Kota Makassar Yusran Jusuf memahami kondisi Makassar. Saya pikir pak Pj juga paham kondisi Makassar, artinya ada memang langkah yang harus ikuti pemerintah pusat, yang bisa kita lihat di Makassar mungkin agak beda kondisi geografisnya sehingga ada langkah lain seorang Pj untuk mengatur itu, kata dia.

Penekanan penyelesaian masalah pada berita keenam yakni, "Perkuat herd Immunity dengan New Normal berbasis kearifan lokal, terlihat pada teks berita:

Penjabat (Pj) Wali Kota Makassar Yusran Jusuf mengatakan, COVID-19 harus dihadapi dengan melakukan adaptasi alias new normal berbasis kearifan lokal dengan memperkuat herd Immunity. Herd immunity itu artinya bagaimana meningkatkan daya tahan tubuh masyarakat dengan memanfaatkan kearifan lokal, memanfaatkan sumber daya sekitar dengan nutrisi fungsional," ujar Yusran di Balai Kota Makassar, Selasa, 26 Mei 2020.

Yusran memaparkan, keputusan tersebut lahir setelah diskusi dengan para pakar. Ia mengatakan, saat ini, yang paling penting adalah meningkatkan imunitas. Selama imunitas tubuh kuat, kata dia, maka yang terinfeksi COVID-19 akan berkurang. "Kita melakukannya di level RT dan RW karena di situlah kekuatan utama masyarakat kita," kata dia.

Dari enam berita yang ditampilkan, Makassar.Terkini.id berupaya menggambarkan sosok Gubernur Sulsel Prof. Nurdin Abdullah sebagai seorang pemimpin yang tegas dan memiliki kendali penuh. Ketegasan Prof. Nurdin Abdullah tercermin pada kutipan atau kalimat langsung dalam penulisan beritanya. Makassar. Terkini.id berupaya untuk menunjukkan kepada pembaca sikap, perasaan, serta emosi yang sedang menyelimuti Gubernur Sulsel Prof. Nurdin Abdullah, atas rumor yang beredar.

Salah satu aspek kontruksi yang ditunjukkan Makassar.Terkini.id adalah melakukan penggambaran tentang sosok Prof. Yusran kepada khalayak dengan menampilkan sosok Pj. Wali Kota Makassar yang teguh atas keputusan yang telah dia rancang. Yusran terlihat tidak merasa khawatir, terganggu atau cemas. Sebaliknya Prof. Yusran gencar menyebutkan inovasi-inovasi kebijakan dalam menangani COVID-19

Makassar Terkini juga memberikan penjabaran kepada khalayak yakni, kebijakan Prof. Yusran mendapat respond dan didukung oleh badan eksekutif, sehingga secara tidak langsung kontruksi yang dibentuk Makassar.Terkini.id merupakan bentuk manipulasi pembaca ke suatu ideologi yang telah dibentuk oleh media.

Pada sisi lain, Makassar Terkini mendramatisasi fakta antara Pj Wali Kota Makassar versus Gubernur Sulsel. Media bisa memperjelas atau mempertajam konflik. Media juga bisa menentukan yang mana dijadikan sebagai pahlawan atau penentang. Reese (2001) menyebutkan peran suatu tokoh, sebagai penonton, pratagonis, atau antagonis terletak pada pembingkaian berita media.

Makassar.Terkini.id memperlihatkan Prof. Nurdin Abdullah mengeluarkan arogansinya, emosi, kekuasaan, dan kendali penuh sebagai orang nomor satu Sulsel, dengan cara terang-terangan menegur pihak-pihak yang tidak sejalan dengan intruksi Pemprov Sulsel, dalam hal ini ditujukan kepada Pj Wali Kota Makassar Prof. Yusran Jusuf.

Tidak hanya itu, pada berita kelima dan keenam, bukannya mempermasalahkan kisruh perseteruan Pj Wali Kota Makassar versus Gubernur Sulsel, sebaiknya Makassar Terkini.id, ingin menunjukkan kepada pembaca, beberapa kebijakan Pj. Wali Kota Makassar Prof. Yusran tidak sejalan dengan Gubernur Sulsel Prof. Nurdin Abdullah. Makassar Terkini cenderung mengangkat citra Pj. Wali Kota, melalui komentar narasumber dalam teks berita yang tertuang dalam kutipan langsung, secara blakblakan menyetujui kebijakan, dan mengapresiasi, sekaligus memberi dukungan terhadap Prof. Yusran. Kecenderungan Makassar Terkini tersebut berpengaruh terhadap pendapat umum (Bungin, 2006).

\section{KESIMPULAN}

Kecenderungan yang ditonjolkan Makassar.Terkini.id dari enam berita yang dianalisis, media online itu terlihat berhati-hati dalam menampilkan pemberitaan yang kontradiksi antara Pj. Wali Kota Makassar versus Gubernur Sulsel. Namun begitu, Makassar.Terkini.id menampilkan adanya kisruh kebijakan antara Pj. Wali Kota Makassar dan Gubernur Sulsel dalam menangani COVID-19.

Berita tersebut tidak menjadi perhatian lagi, dan seakan-akan polemik tersebut ditutupi atau dilemahkan dengan munculnya beberapa berita yang cenderung mendukung langkah Prof. Yusran. 
Kecenderungan itu, terlihat dari komentar narasumber yang sama sekali tidak merespond perseteruan tersebut, bahkan sebaliknya terus menyebutkan kebijakan Prof. Yusran dalam kutipan langsung berita.

Makassar Terkini.id membentuk kontruksi beritanya, cenderung berpihak pada Prof. Yusran itu terlihat dari pemilihan narasumber dan komentar narasumber. Makassar Terkini.id, cenderung mengarahkan narasumber untuk tidak mengomentari kisruh antara Pj Wali Kota Makassar dan Gubernur Sulsel. Namun sebaliknya, hanya mengangkat citra Prof. Yusran dengan inovasi-inovasi kebijakan dalam mengendalikan COVID-19 di Kota Makassar.

Ada beberapa faktor yang mempengaruhi kecenderungan tersebut pertama, mengandung nilai berita, prominence. Pj. Wali Kota dan Gubernur Sulsel merupakan sosok yang dianggap penting, sehingga kebijakan mereka selalu diberitakan. Tidak hanya itu, peristiwa tersebut juga melibatkan dua kepala daerah yang menarik perhatian masyarakat. Sosok kedua tokoh tersebut, dimanfaatkan media untuk selalu me-update pemberitaan terkait kedua kepala daerah tersebut. Pemberitaan $\mathrm{Pj}$. Wali Kota dan Gubernur Sulsel mengandung nilai berita konflik yang secara nilai berita, lebih menarik daripada berita seremonial.

\section{DAFTAR PUSTAKA}

Achmad, M., Mayasari, \& Siti, N. (2020). Analysis of Tirto.id and Kumparan Framing on the Reporting of Habib Bahar's Hate Speech Case. Lontara, 8(1).

Alex, S. (2009). Media Text Analysis: An Introduction to Discourse Analysis, Semiotic Analysis, and Framing Analysis. Bandung: PT Remaja Rosdakarya.

Ammar, P., \& Dewi, K. (2020). Analysis of the Reporting Framework for Millennial Generation and Government About COVID-19 on Social Media. Chancel, 37(1..

Ardhina, P. (2018). Framing Analysis of LGBT News in Republika and BBC News Model Robert N. Entman. Thaqãfiyyãt, 19(1), 18-20.

Bungin, B. (2006). Sociology of Communication. Jakarta: Kencana Prenada Media Group.

Charles, W. (1985). Sociology of Mass Communication, translated by Jalaluddin Rakhmat. Bandung: Youth Work.

Eriyanto. (2002). Analysis of Construction Framing, Ideology, and Media Politics. Yogyakarta: PT LkiS Printing Cemerlang.

Eriyanto. (2009). Analysis of Framing, Construction, Ideology, and Media Politics. Yogyakarta: LKiS. Eriyanto. (2011). Framing Analysis of Ideological Construction and Media Politics. Bandung: Lkis.

Eriyanto. (2019). Media and Public Opinion How the Media Create Issues (Agenda Setting), Framing and Directing Public Views (Priming). Depok: Rajawali Press.

Granato, L. (2020). Newspaper Feature Writing. Australia University of New South. Wales: Ltd. Press.

Hamad, I. (2004). Political Reality Construction in Mass Media; A Critical Discourse Analysis Study of Political News. Jakarta: Granite.

Henny, SK, Nuryani, TR, \& Retno, H. (2019). Analysis of Setya Novanto's e-KTP Corruption News Framing on Online Media. ACCOMAC, 2, 54.

Karman. (2013). Mass Media and Construction Reality (Framing Analysis of the Reporting of the Ministerial Decree on Ahmadiyah in Indonesia in the Daily Newspapers of Suara Pembaruan and Republika. Journal of Communication and Media Studies, 17(2), 174.

Kheyene, MB, Mutia, RP, \& Nalal, M. (2020). Analysis of the Reporting Framing of Millennial Generation and the Government regarding COVID-19 in Online Media. Journal of Communication Science, 4(1), 86.

M., GY, Riris, L., Genep, S., Roswita, O., \& Lusia, S. (2020). The Challenge of Peace Journalism in the Post Region. Journal of Communication Research and Public Opinion, 24(1), 35.

Margianto, J., \& Syaefullah, A. (2012). Online Media: Readers, Profits, and Ethics, Problems of Online Journalism Practices in Indonesia. Jakarta: Indonesian Independent Journalists Alliance.

Muhaemin, E., \& Sanusi, I. (2019). Religious Intolerance in the Framing of the Kompas Newspaper. Communicatus: Journal of Communication Studies, 3(1), 21.

Rank, A. (2020, November 11). Alexa. Taken back from Alexa Rank Indonesia: https://alexa.bukamatanews.id/

Reese, SA (2001). Framing Public Life: Perspectives on Media and Our Understanding of the Social World. New Jersey: Lawrence Erlbaum Associates. 
Riky, R. (2020). Analysis of News Content About the Application of New Normal in Indonesia on Tirto.id Media. Audience Journal, 1(2), 244.

Riky, R. (2020). Media Objectivity in the Middle of the COVID-19 Pandemic Analysis of News Content About the Implementation of the New Normal in Indonesia on Tirto.id Media. Audience, 1(2), 244.

Romli, A. (2012). Online Journalism: A Guide to Managing Online Media. Bandung: Cendikia

Ronda, M. (2018). Contemporary Interpretation of Communication Science. Tangerang: PT. Indigo Media.

Ruri, H., Zainal, AA, \& Airlangga, B. (2020). Analysis of Framing News of the Termination of PSBB Surabaya Raya in Online Media Kompas.com and SuaraSurabaya.Net. Journal of Communication Science, 10(2), 159.

Siregar, A. (2007). How to cover and write news for the mass media. Yogyakarta: Kanisius.

Sobur, A. (2006). Media Text Analysis, An Introduction to Discourse Analysis, Semiotic Analysis and Framing Analysis. Bandung: Youth Rosdakarya.

Sophia, D., Ira, DM, \& Dedi, KP (2016). Robert N. Entman's Framing Analysis of the Reporting on the Jakarta Bay Reclamation in Tempo Magazine. e-Proceeding of Management, 3(3), 30.

Xena, LA (2014). Framing Analysis of the Statement of Sosok Basuki Tjahaja Purnama (Ahok) In Online Media. Journal E-Communication, 2(1), 1.

Zainal, AA (2019). The Attitude of the Muslim Community Practitioners of Yoga in Surabaya About the Fatwa News MUI is Forbidden Yoga. Journal of Communication Science, 1(2), 113. 